\title{
Stimulus and response concreteness, imagery, and temporal factors in paired-associate learning'
}

\author{
A. DANIEL YARMEY, BRIAN J. O'NEILL, ${ }^{2}$ and DICK de \\ $R Y K$, University of Guelph, Ontario, Canada
}

This study investigated the effects of recall rates $(2: 3-\mathrm{sec}$ vs 2:5-sec vs 2:8-sec), length of between-trial intervals (none vs $10 \mathrm{sec}$ vs $60 \mathrm{sec}$ ), and noun concreteness on paired-associate learning. Ss learned a list of concrete-concrete, concreteabstract, abstract-concrete, and abstract-abstract nouns. The results indicated that concrete nouns, particularly on the stimulus side of pairs, facilitated recall. Intertrial intervals yielded no significant effect on recall. The failure to find significant differences attributable to recall rates was discussed in reference to a previous study which found differences in learning abstract and concrete noun stimuli as a function of duration of input or study intervals.

Numerous investigations (see Paivio, in press) have indicated that concrete in comparison to abstract nouns function as superior stimulus cues for their associates in paired-associate learning (PAL). The phenomenon has been attributed to the capacity of concrete nouns to elicit sensory images which serve to mediate response retrieval. Paivio (in press) has theorized that imaginal mediation involves multiple coding and decoding stages (from words to images and back to words). Temporal factors of study-recall intervals may be assumed to interact with concreteness (C) factors. Yarmey (1967) found such effects when length of learning intervals was varied. The present study investigated PAL as a function of Noun C, length of recall intervals, and length of between-trial intervals. Concrete word pairs are more likely to evoke imaginal than verbal mediators while the reverse is true of abstract word pairs (Paivio, Yuille, \& Smythe, 1966). A test for reaction time (RT) by Paivio (1966) showed that image arousal was slower than verbal association to both concrete and abstract words; the concrete-abstract RT difference was much greater for imaginal than for verbal associative responses. Yuille \& Paivio (1967) found that latency scores for discovery of verbal mediators did not differ between concrete noun pairs and abstract noun pairs. Paivio \& Csapo (in press) investigated memory for pictures, concrete words, and abstract words at fast $(3 / 16-\mathrm{sec})$ and slow $(1 / 2-\mathrm{sec})$ presentation rates. Measures were taken of memory span, free recall, recognition memory and serial learning. In general, memory for pictures was superior to concrete words and abstract words at the slow rate, but inferior at the fast rate. Memory for concrete words and abstract words was similar at the fast rate but concrete words were superior to abstract at the slow rate. These findings on memory are congruent with the RT data. Since imaginal mediators should not be available for learning of concrete nouns at fast presentation rates but verbal mediators would be equally available it follows that PAL should not differ for concrete-concrete (C-C), concrete-abstract (C-A), abstractconcrete $(\mathrm{A}-\mathrm{C})$, and abstract-abstract (A-A) noun pairs at a fast rate. At slow rates, C-C and C-A pairs should be better recalled than $\mathrm{A}-\mathrm{C}$ and $\mathrm{A}-\mathrm{A}$ pairs since stimulus-elicited mediating imagery would enhance response retrieval.

Yarmey (1967) found that recall of abstract noun-nonsense syllable pairs learned at a $5: 5-\mathrm{sec}$ presentation rate was superior to recall of concrete noun-syllables learned at a 3:5-sec rate. It was expected that A-C and A-A PA learning at a slow rate would allow more time for verbal mediated retrieval and therefore superior recall than $\mathrm{C}-\mathrm{C}$ and $\mathrm{C}-\mathrm{A}$ pairs at a fast rate. The latter two S-R combinations would have less time for verbal mediation than that given to $\mathrm{A}-\mathrm{C}$ and $\mathrm{A}-\mathrm{A}$ pairs and insufficient time for imaginal mediation.

Forgetting may occur very rapidly depending upon the stimulus attributes of the materials employed and the conditions under which learning occurs. Yarmey (1967) found no loss in recall as the length of between-trial intervals was increased. No difference in recall scores was expected in the present study as a function of increased delay intervals.

\section{METHOD}

\section{Subjects}

Forty-eight female and 42 male summer school students served as Ss. In order to simplify the statistical analysis, a uniform size of $10 \mathrm{Ss}$ per group was achieved by random elimination of six additional Ss. Participation in the experiment was voluntary and Ss were assigned to experimental groups in order of appearance at the laboratory. Testing of Ss was conducted individually or in groups ranging in size from two to five persons.

Materials

The PA list (List A) consisted of 16 pairs, four of each of the combinations: $\mathrm{C}-\mathrm{C}, \mathrm{C}-\mathrm{A}, \mathrm{A}-\mathrm{C}$, and $\mathrm{A}-\mathrm{A}$. The pairings were random with the restriction that no obvious associations existed between the nouns. A second list (B) was created by reversing the stimulus-response position of the pairs from the first list. The concrete and abstract nouns were chosen from the Paivio, Yuille, \& Madigan (1968) norms. The mean imagery and concreteness scores of the concrete nouns are 6.18 and 6.69 , respectively, and of abstract nouns, 3.17 and 2.34. The mean meaningfulness score of the concrete nouns is 6.04 , of the abstract nouns, 5.95. The mean word length for both concrete and abstract nouns is 6.69 letters. The mean word frequencies according to Thomdike-Lorge (1944) are 48.37 for concrete words and 42.87 for abstract words, AA and $A$ words being assigned values of 100 and 50 , respectively. Procedure

The pairs were presented orally by a tape recorder for four study- (both stimulus and response members presented) recall (stimulus members only presented) trials. Eight randomizations of the position of items were made to minimize serial learning. Ss recorded their responses on a four-page booklet, each page representing one trial. The numbers, 1-16, appeared in a column along one side of each page showing where responses were to be written. To aid the recording of responses, the guide number was read aloud immediately before the presentation of each stimulus during recall. Half of the Ss learned PA List A or B at one of three recall rates: 2:3 sec, $2: 5 \mathrm{sec}$, and $2: 8 \mathrm{sec}$. The 2:3-sec rate was considered to be fast for PAL, since Ss were required to retrieve and write their responses during recall. Corrections or additions were not allowed to be made at a later time. Three intertrial intervals were employed: none, $10 \mathrm{sec}$, and $60 \mathrm{sec}$, resulting in the formation of nine experimental conditions. A digit cancellation task was used to prevent rehearsal during the intertrial intervals.

\section{RESULTS AND DISCUSSION}

The total number of correct responses for each S-R combination, based on four trials and four pairs, was analyzed by a 3 by 3 by 2 by 2 analysis of variance. The major variables were Recall intervals and Intertrial intervals (both treated as between-Ss factors) and Stimulus $\mathrm{C}$ and Response $\mathrm{C}$ (within-Ss factors). The counterbalancing procedure involving Lists $A$ and $B$ was not treated as a variable. Significant main effects were found for Stimulus $C(F=99.25$, df $=1 / 81, p<.001)$ and 
Response $\mathrm{C}(\mathrm{F}=39.55$, df $=1 / 81, \mathrm{p}<.001)$. The main effect of Recall intervals was not significant $(F<1.00)$, nor, as predicted, was the effect of Intertrial intervals $(F<1.00)$. A significant interaction of Stimulus $C$ by Response $C(F=7.31$, df $=1 / 81, p<.01$ ) indicated superior learning in the predicted order: C-C, C-A, A-C, and A-A pairs. This was confirmed by individual $t$ tests for correlated means which yielded significant differences at the .01 level of confidence or better between each type of paired nouns. No other interactions of the analysis of variance were significant.

The results are similar to those of previous investigations; Noun $\mathrm{C}$ had a facilitating effect on PAL, particularly on the stimulus side of pairs. The hypothesis that temporal factors would interact with Noun $C$ and stimulus-response position of nouns during recall was not supported. In contrast to the results of Yarmey (1967), no difference was found in learning abstract pairs at a longer presentation rate as opposed to concrete pairs at a shorter rate. Besides the fact that the former study employed noun-syllable pairs as opposed to the noun-noun pairs of the present study a key difference was the longer input or study interval used ( 5 and $3 \mathrm{sec}$ vs $2 \mathrm{sec}$ ). The total learning time in both studies at the long rate was $10 \mathrm{sec}$ (5:5 vs 2:8). The failure to find a significant interaction of $\mathrm{C}$ by Rate in the present study in contrast with the significant interaction of these two factors in the Yarmey (1967) study suggests that more attention be given to the effects of length of input interval on mediational processes and PAL. It is possible that coding and decoding processes of verbal and nonverbal symbols are initiated during the input stage or storage stage and are not restricted solely to retrieval.
Paivio and his colleagues usually present the concretenessabstractness materials at a $2: 8$-sec rate. In terms of efficiency of design, the present study suggests that shorter recall intervals may be employed with equivalent results.

\section{REFERENCES}

PAIVIO, A. Latency of verbal associations and imagery to noun stimuli as a function of abstractness and generality. Canadian Journal of Psy chology, 1966, 20, 378-387.

PAIVIO, A. Mental imagery in associative learning and memory. Psy chological Review, in press.

PAIVIO, A., \& CSAPO, K. Concrete-image and verbal memory codes. Journal of Experimental Psychology, in press.

PAIVIO, A., YUILLE, J. C., \& MADIGAN, S. A. Concreteness, imagery, and meaningfulness values for 925 nouns. Journal of Experimental Psychology Monograph Supplements, 1968, 76, No. 1, Part 2.

PAIVIO, A., YUILLE, J. C., \& SMYTHE, P. C. Stimulus and response abstractness, imagery, and meaningfulness, and reported mediators in paired-associate learning. Canadian Journal of Psychology, 1966, 20, 362-377.

THORNDIKE, E. L., \& LORGE, I. The teacher's word book of 30,000 words. New York: Bureau of Publications, Teacher's College, Columbia University, 1944.

YARMEY, A. D. Concreteness, imagery and temporal factors in paired-associate learning. Psychonomic Science, 1967, 8, 417-418.

YUILLE, J. C., \& PAIVIO, A. Latency of imaginal and verbal mediators as a function of stimulus and response concreteness-imagery. Journal of Experimental Psychology, 1967, 75, 540-544. NOTES

1. This study was supported by a grant from the National Research Council of Canada (Grant APA-288) to the senior author.

2. Now at the University of Western Ontario. 